\title{
THE SHORT LATENCY DISCHARGE OF HIGH LIGHT-THRESHOLD IN THE RABBIT OPTIC NERVE
}

\author{
Daizo Yonemura AND Yutaka Tsuchida \\ Department of Ophthalmology, The School of Medicine, \\ Kanazawa University, Kanazawa
}

The analysis of the optic nerve discharges elicited by photic stimulation has been the subject of a large number of investigations and this work has been reviewed (GRANIT, 1947, 1959, 1962 ; Múller-Limmroth, 1959). The lightinduced optic nerve discharge was recorded from cold-blooded animals (ADRIAN, and Matthews, 1927a, 1927b ; Bernhard, 1940, 1942; Hartline, 1938) and from mammals (BARTLEY and Bishop, 1942; AdRIAN, 1946; NoEll and CHINN, 1950 ; Noell, 1953; Thomson, 1953 ; Schubert, 1953; Lennox, 1958; Doty and KIMURA, 1963 ; Doty, Kimura and Mogenson, 1964; Ponte and Monaco, 1964 ; YoKoyAmA, KANEKo and NAKAI, 1963 ; STEINBERG, 1966).

In the rabbit the ordinary pattern of the compound optic nerve response induced with a single light pulse presents the early-on-wave succeeded by the late-on-wave and off-response (BARTLEY and Bishop, 1942). Additionally several wavelets may appear superimposed on the early-on-wave (BARTLEY and Bishop, 1942; Crapper and Noell, 1963; Yokoyama, KANeko and NAKAI, 1964).

Since the discovery of the early receptor potential (ERP) in the monkey retina by Brown and MurAKAmi (1964a, 1964b), extremely intense flash stimuli have been used for retinal stimulation to approach this matter. The ERP has been documented in a wide variety of vertebrates, including man (Yonemura, KAWASAKI and Hasui, 1966; KAWASAKI, 1966; Yonemura and KAWASAKI, 1967 ; GALlOWAY, 1967).

Despite numerous experiments directed at the retinal responsiveness to intense light stimuli little is known regarding the optic nerve potential in response to such strong stimuli. Some experiments on this line have been done on rabbits (Yonemura and Tsuchida, 1967; Yonemura,TsuchidA, FujMURA and YAMADA, 1967). With strong flash stimuli they showed, in the compound potential of the optic nerve of the rabbit, a new potential which

Received for publication January 11, 1968

米村大蔵, 土田 豊 
has a latency of about $4.5-5.0 \mathrm{msec}$ and precedes the ordinary early-on-wave in the optic nerve potential. In their papers the new potential is labeled the early optic nerve potential (EONP).

The present work was undertaken to describe this early component found in the rabbit optic nerve, in an attempt to infer its functional and pharmacological properties.

\section{METHODS}

Ninety albino rabbits of both sexes, weighing $2-3 \mathrm{~kg}$, were used in this study. The animals were preliminarily anesthetized with ether. The site of surgery was infiltrated with procaine. The trachea was cannulated. Both nictating membranes were excised. In a number of instances the fellow eye was enucleated. At the completion of surgery the animal was paralyzed by injection of gallamine triethiodide (Flaxédil) intravenously and thereafter artificially ventilated. The head was firmly clamped in a stereotaxic instrument. Throughout the course of the experiment the electrocardiogram was monitored, and the body temperature was controlled within normal limits. Experiments on animals were carried out in a dark, electrically screened room after a preliminary darkadaptation of about 30 minutes.

The stimulus for the ERG and optic nerve response was a single flash of essentially white light from a xenon condenser-discharge tube which was operated at an input energy of 80 joules in most of experiments, and delivered every two or three minutes. The flash was effectively dissipated in $0.8 \mathrm{msec}$, the peak luminance occurring after 0.3 msec. The light was guided to the eye by means of a $6 \mathrm{~mm}$ diameter fiber optics bundle $50 \mathrm{~cm}$ in length. The end of this bundle was as close as possible to the cornea, and the other end was placed close to the xenon lamp. The filters which exclude wavelengths shorter than $420 \mathrm{~m} \mu$ and longer than $800 \mathrm{~m} \mu$ were put in the light path. The intensity of photic stimulation could be modified over a $10 \log _{10}$ units range by interposing neutral density filters between the flash tube and the fiber optics bundle. Stimulus intensities are represented in log units below the maximum intensity $(0.0 \mathrm{log}$ unit $)$ unless otherwise specified.

The ERG was recorded with a saline-soaked black cotton wick electrode resting on the rim of the cornea. A similar reference electrode was placed on the frontal bone exposed surgically. The light-induced population response of the optic nerve was picked up in the cranial cavity. The rostral pole of the cerebral hemispheres were aspirated with a small suction tip to expose the intracranial portions of the optic nerves on both sides. The electrode was introduced to the optic nerve by direct insertion through the intact surface. In most of the experiments, responses were picked up with a tungsten needle electrode sharpened to tip diameters of $50 \mu$ with $0.1 \mathrm{~mm}$ tip exposures. The distance between the electrode tip and the posterior pole of the eyeball was about $12 \mathrm{~mm}$. Responses were monopolarly referred to a black cotton wick electrode put on the frontal bone surgically exposed. In other instances a pair of insulated metal electrodes cemented side by side with bare tips $0.2 \mathrm{~mm}$ apart was employed. Tungsten microelectrodes of 3-7 megohms resistance were used for registering discharges of optic nerve fibers.

Potentials were led off to a conventional CR-coupled amplifier with a cathode follower input and displayed on a dual beam cathode ray oscilloscope. The upper beam of the oscilloscope served for registering the ERG, and the lower one for recording the potentials relevant to optic nerve activity. Positivity was presented upward in all records, following the convention for the ERG. 


\section{ERG}

ERGs were taken at stimulus intensities ranging from $-7.0 \mathrm{log}$ units to $0.0 \mathrm{log}$ unit in the dark (FIG. 1). On weak illumination a monophasic positive potential (b-wave) was observable. At an intensity of about $-5.0 \log$ units the ERG seemed to begin with a small negative deflection (a-wave) followed by a large b-wave. At higher intensities ( -3.5 to $0.0 \log$ unit) a series of wavelets (the oscillatory potential) was seen, being superimposed on the rising phase of the b-wave. The general form of the recorded ERG is in good agreement with that described in detail elsewhere (Yonemura, Masuda and HatTa, 1963). With stimulus intensities ranging from -1.1 to $0.0 \mathrm{log}$ unit an early potential was recordable preceding the a-wave associated with the b-wave on which the oscillatory potential rode (FIG. 1). At such intensities the a-wave

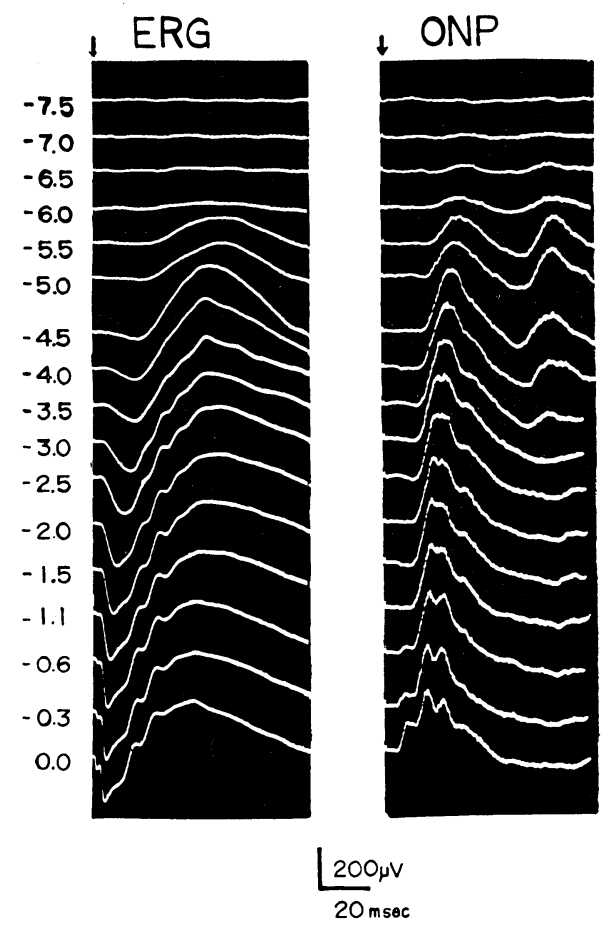

FIG. 1. Effects of stimulus intensity on the ERG and optic nerve potential of the albino rabbit. The experiments were performed in a dark room. Photic stimulus is indicated by an arrow. Numerals at left indicate $\log$ stimulus intensities. An intensity of $0.0 \mathrm{log}$ unit is roughly 108.5 times the scotopic b-wave threshold. Time constant: $0.03 \mathrm{sec}$. Positivity: upwards. Explanation in text.

was found to present a minimum latency which depended upon the state of adaptation. This value was recognized to be smaller in the dark-adapted eye than in the light-adapted eye. In fully dark-adapted animals in good condition, the value could be reduced to about $1.6 \mathrm{msec}$ (YoNEMURA, TSUCHIDA and FUJIMURA, 1967) which is probably the shortest latency thus far obtained for the a-wave in the rabbit ERG, and this quantity is close to the minimum latency of the a-wave in the dark-adapted ERG reported for man $(1.7 \mathrm{msec}$, 
YONEMURA and KAWASAKI, 1967) or the monkey (1.5 msec, BROWn, WATANABE and Murakami, 1965) in which an origin of the a-wave is assumed to be localized in the retinal receptors. In vertebrates, e.g. the cat, monkey and some cold-blooded animals, the leading edge of the a-wave is regarded as an index of photoreceptor activity (BROWN and WIESEL, 1961; BROWN, WATANABE and Murakami, 1965; Yonemura and Hatta, 1966a, 1966b; Murakami and KANEKO, 1966a, 1966b). The preceding considerations may point to an origin of the a-wave in the rabbit ERG in the visual cells.

The inter-peak periods of the oscillatory potential remained nearly unaltered with little regard to stimulus intensities used. This result confirms and extends, over a wider range of intensity, the findings reported previously by Yonemura, MAsuda and HATta (1963).

The b-wave becomes saturated beyond a certain intensity $(-4.5 \log$ units) as seen in FIGS. 1 and 2. This figure shows further that the a-wave forms a plateau at higher intensities ( -1.0 to $0.0 \mathrm{log}$ unit).

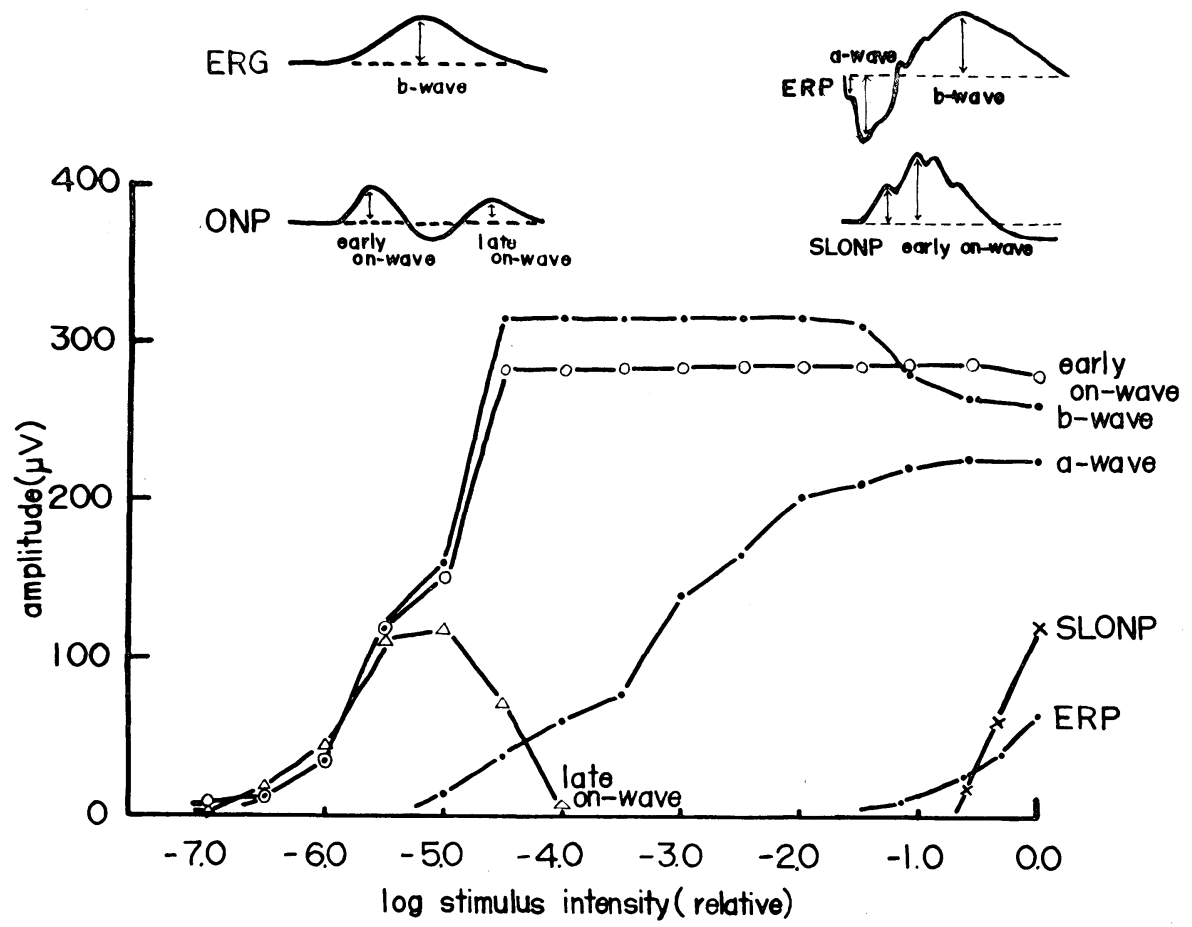

FIG. 2. Amplitudes of the negative phase of the early receptor potential (ERP), the a-wave and b-wave in the albino rabbit ERG, and amplitudes of the short latency optic nerve potential (SLONP) and the early-on- and late-on-waves in the optic nerve response of the albino rabbit as functions of the log stimulus intensity. The data for these potentials were obtained from a single rabbit. Amplitudes were measured from the baseline as shown in the diagram. Explanation in text. 
This study has confirmed the findings by KAWASAKI (1967) that (1) the early potential in the dark-adapted albino rabbit ERG is substantially biphasic, consisting of a small positive hump succeeded by a negative deflection which was followed in turn by the a-wave, and (2) the latency of the positive phase of the early potential was less than $30 \mu \mathrm{sec}$, and its peak latency about 120 $\mu$ sec. In FIG. 1 the positive deflection was so small that it was almost missing. The amplitude of the early potential rose above the experimental noise level (about $5-10 \mu \mathrm{V}$ in these experiments) only at extremely high intensities. The summit of the negative phase of the early potential occurred approximately $800 \mu \mathrm{sec}$, after the flash light. The two peak latencies did not appear to depend on the stimulus flash energy, although the size of the early potential was augmented as the stimulus energy increased. The amplitude of the negative deflection $\left(R_{2}\right)$ was found to be approximately proportional to stimulus intensity, leastwise for the first $1.0 \mathrm{log}$ unit above the threshold, which was assessed on the basis of a $5 \mu \mathrm{V}$ criterion. As to the amplitude vs intensity relationship for the positive component no explicit statement is given in the present study, because the component was so small in this experiment that it was hardly possible to judge accurately the size of the amplitude. In another series of experiments the early potential was proved to be far less susceptible to anoxia than the subsequent ERG components such as the a-, b-waves and the oscillatory potential. The early potential could survive as long as half an hour or more after the death of the animal, whereas the other ERG constituents disappeared within several minutes following death.

The early potential of the albino rabbit characterized above, resembles the early receptor potential defined in the retinae of other vertebrate species (Brown, Watanabe and Murakami, 1965; Cone, 1964, 1965; PaK and Cone, 1964) in that, (1) it is independent of stimulus intensity in time course and has a similar time course to that of the early receptor potential, (2) it has an extremely high threshold which is more than $10^{7}$ times that for the scotopic b-wave, (3) the depth of its cornea-negative swing $\left(R_{2}\right)$ is primarily proportional to the stimulus energy up to a limit (see CONE, 1964, 1965; BROWN and CRAWFORD, 1967b), and (4) it is highly resistant to anoxia.

The possibility that the early potential in the living albino rabbit might be significantly contaminated by potentials from the "pigment epitheliumchoroid complex" (BROWN, 1965; BROWN and GAGE, 1966; BROWN and CRAWFORD, 1967a, 1967b; EBREY and CONE, 1967) is probably precluded, because the albino rabbit is free of melanin (E. YAMADA, personal communication), a possible pigment for the "pigment epithelium-choroid complex response" as pointed out by EBrey and CONE (1967) and Brown and CRAWFORd (1967b). Based on the foregoing arguments, we may assume that the early potential in the ERG of the living albino rabbit corresponds essentially to the early receptor potential fully delineated by CoNe (1965) in the albino rat. 


\section{Optic nerve response to retinal illumination}

Combined recordings of the ERG and light-induced optic nerve response were made. The light-induced optic nerve potential was recorded monopolarly in albino rabbits at stimulus intensities ranging from -7.0 to $0.0 \log$ unit in darkness. At low intensities the response of the optic nerve manifested positive components, i. e. the early- and late-waves (FIG. 1). As seen in FIG. 2, the amplitude of the late-waves was presented in a sigmoidal function with respect to the $\log$ of stimulus intensity for the initial $2.0 \mathrm{log}$ units above the threshold. At higher intensities $(-4.5$ to $-3.0 \mathrm{log}$ units) the late-on-wave was depressed (FIGS. 1 and 2). This component cannot be the off-response connected with the termination of stimulus light, since the off-response should not be reduced at such intensities (cf. BARTLEY and BISHOP, 1942). As for the early wave the amplitude vs log intensity curve was also S-shaped (FIG. 2). This potential attained the maximum voltage at a level of about $-4.5 \log$ units and then it maintained this value at higher stimulus intensities. The early wave was found to be more resistant to anoxia than the late wave. Judging from the fact that the early and late waves differ in amplitude vs intensity relationship (suppression of the late wave with high intensities) and in susceptibility to anoxia (rapid disappearance of the late wave), it may be considered that the early and late waves observed here are identical with respectively the early-on- and late-on-waves thoroughly described in the compound spike potential of the rabbit optic nerve by BARTLEY and BISHOP (1942), ADRIAN (1946) and Noell (1953). At intensities above - 3.5 log units rhythmic wavelets overlying the early-on-wave were observable. It is noted that the threshold of the rhythmic wavelets appeared to approximate that of the oscillatory potential in the ERG. The oscillatory nature of the light-induced compound potential in the optic nerve was noticed similarly in the cat (OGAwA, BISHOP and Levick, 1966 ; Steinberg, 1966). As the stimulus intensity was intensified, the latency of the early-on-wave diminished gradually to attain a minimum value of about $11 \mathrm{msec}$. This seems the shortest latency thus far offered for the early-on-wave in the rabbit optic nerve potential, since a value of $13 \mathrm{msec}$ has been proposed as the shortest latency for the early-on-wave in the rabbit (YoKOYAMA, KANEKO and NAKAI, 1963). Occasionally a slow negative swing with a peak latency of around $100-200$ msec was registered following the onwaves of the optic nerve potential with a needle electrode placed in the intracranial part of the nerve. Yonemura, Tsuchida, YAmada and Fujimura (1967) deduced that the slow negative potential in study originates neither in the optic nerve nor in the retina, but probably somewhere proximal to the optic nerve tract. With further increase of intensity a rapid potential was deduced unmistakably preceding the early-on-wave having the minimum latency (about $11 \mathrm{msec}$ ), provided that the electrode tip was located in the central and/ or ventral area of the optic nerve (FIGS. 1, 3 and 4). The response encountered 


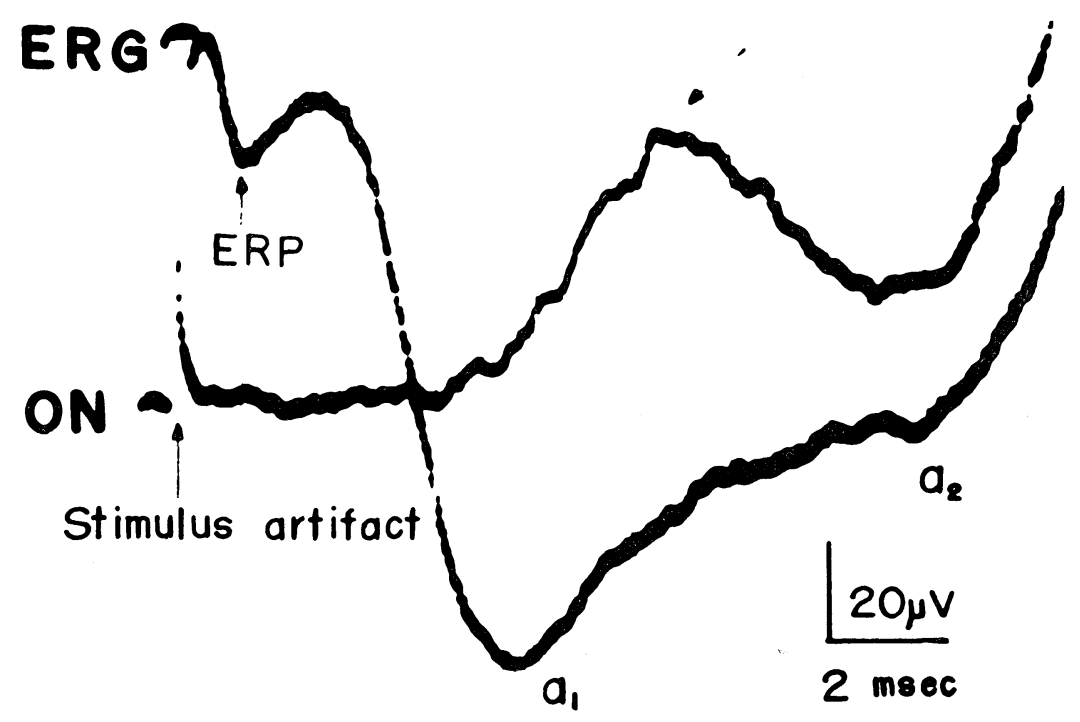

FIG. 3. Combined recording of the ERG and optic nerve potential of the albino rabbit. The ERG (upper trace) begins with the early receptor potential (ERP) followed by the a-wave showing two troughs $\left(\mathrm{a}_{1}\right.$ and $\left.\mathrm{a}_{2}\right)$. The lower trace represents the short latency optic nerve potential (SLONP) followed by the early-on-wave. The SLONP is indicated by an arrow. As for the early-on-wave, only the initial segment is illustrated in this figure. The SLONP has a latency of about $4.5 \mathrm{msec}$ and a crest time of about $8.0 \mathrm{msec}$, followed by the early-on-wave having a latency of about 11 msec. Stimulus intensity: $0.0 \mathrm{log}$ unit. Time constant: $0.3 \mathrm{sec}$. Positivity : upwards.

was almost entirely positive in polarity, and could not be detected unless the light stimulus was intense enough to evoke an ERP of considerable size. The latency and peak latencies of the above mentioned potential found in the optic nerve were nearly $4.5-5.0 \mathrm{msec}$ and roughly $8.0-8.5 \mathrm{msec}$ respectively at a tentative estimate (FIGS. 1 and 3). The latency tended to decrease in a small degree with the increase of stimulus intensity. This short latency component differs distinctly in time course not only from the ERP, but also from the sequential ERG constituents. The existence of the rapid response in the optic nerve could be verified by bipolar recording as well. The new event which is designated as the early optic nerve potential in the previous reports (YONEMURA, Tsuchida, FujImura and Yamada, 1967; Yonemura and Tsuchida, 1967) may be labeled provisionally the short latency optic nerve potential (SLONP) in the present study. Sometimes small ripples were seen superimposed on the SLONP. The SLONP was scarcely be detected in the dorsal area of the optic nerve, where the early-on-wave was consistently recognized. The SLONP would be hardly complicated by the possible presence of slow potentials such as the "electrotonic potential" pointed out in the optic nerve (BERNHARD, 1940, 1942), "surround negativity" which is assumed to arise in the optic nerve fiber layer of the retina (ARDEN and BROWN, 1965) and the slow 
A

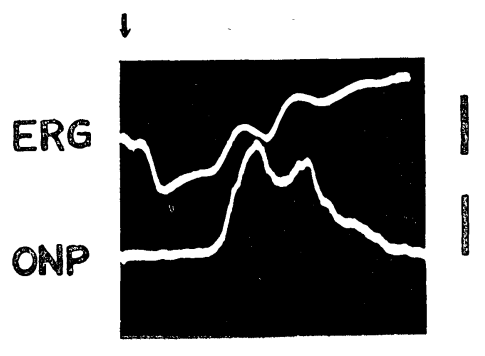

B

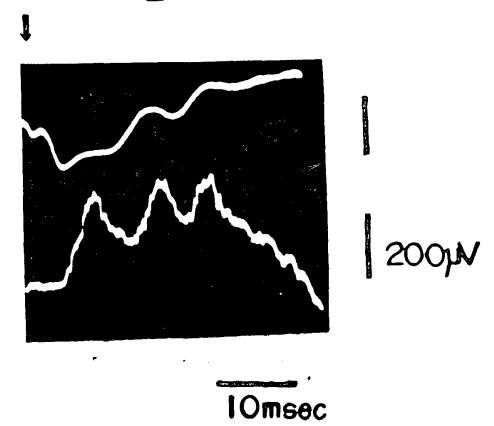

FIG. 4. Combined recording of the ERG and optic nerve potential of the albino rabbit. Records were taken from a dorsal portion (A) and a central and/or ventral portion (B) of the optic nerve bundle of the same rabbit. Record A: The optic nerve potential begins with the early-on-wave having a latency of about $11 \mathrm{msec}$, but the short latency optic nerve potential (SLONP) is not seen. Record B: The optic nerve potential begins with the SLONP having a latency of about $4.5 \mathrm{msec}$, and being followed by the early-on-wave. ERGs (upper traces) are started by the early recepter potential (ERP), which is followed by the ordinary ERG components (the aand $b$-waves and the oscillatory potential). Photic stimulus is indicated by an arrow. Stimulus intensity : $0.0 \mathrm{log}$ unit. Time constant: $0.3 \mathrm{sec}$. Positivity : upwards.

negative potential recordable in the optic nerve (Yonemura, TSUCHIDA, YAMADA and FUJIMURA, 1967), because the SLONP responds too early and fast to be significantly involved in those slow deflections.

The relation between the amplitude of the SLONP and the log of stimulus intensity should be primarily sigmoidal in form, and the height of the SLONP appeared to be linearly related with the $\log$ of stimulus intensity for about one $\log$ unit in the dynamic range where the slope of amplitude vs log intensity curve is steepest (FIGS. 2 and 5). But the intensity which was extrapolated at about $-0.8--0.7 \mathrm{log}$ unit by use of data presented in FIG. 2 may be regarded, roughly speaking, as an approximate quantity of the threshold for SLONP, though the value obtained in this fashion might excell somewhat the actual threshold. The threshold for the SLONP was more than $10^{6.5}$ times that of the early-on-wave.

In a series of experiments the effects of unilateral optic nerve section were investigated. Immediately after the ipsilateral optic nerve had been cut through intracranially between the eyeball and the recording electrode tip, all optic nerve responses, including the SLONP, vanished. For the meantime, the ERG underwent no noticeable change. Both the SLONP and subsequent optic nerve potentials, however, could survive without any visible alterations when the optic nerve had been transected posterior to the position of the electrode tip. These findings may refute the possibility that the SLONP as obtained intracranially is vitiated by the physical spread of light-induced potentials 


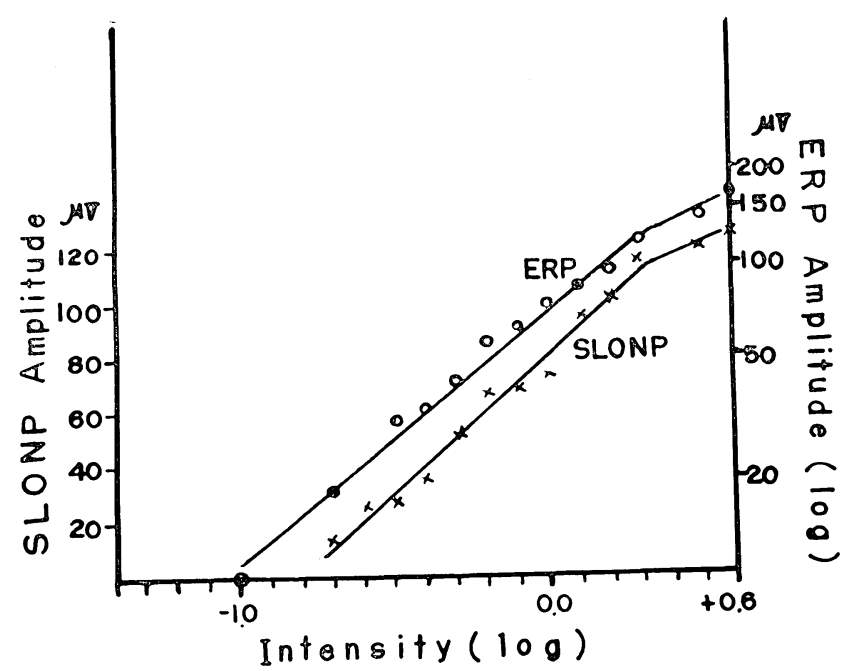

FIG. 5. Amplitudes of the negative component of the early receptor potential (ERP) and short latency optic nerve potential (SLONP) of the albino rabbit as functions of the log stimulus intensity. ERP amplitude is represented by log scale. An intensity of $+0.6 \mathrm{log}$ unit is roughly $10^{9.1}$ times the scotopic b-wave threshold. Explanation in text.

arising in sites such as the retina and the brain through the surrounding tissues, and are not compatible with the view that there is a certain centrifugal influence upon the SLONP. Additional evidence for the first conclusion can be consistent with the results from the pharmacological experiments in which the actions of some nerve blocking drugs on the optic nerve activity and ERG were examined. In some instances $100 \mu \mathrm{l}$ of $2 \%$ lidocaine was injected in the vitreous body through a $0.4 \mathrm{~mm}$ diameter injection syringe inserted into the globe near the equator. In other instances $100 \mu \mathrm{l}$ of $10^{-4} \%$ tetrodotoxin which is known to suppress selectively the generation of nerve impulses without affecting the resting membrane potential in extremely low concentrations (NAKAMURA, NAKAJIMA and GRUNDFEST, 1965) was applied to the retina in the same manner. Crystalline tetrodotoxin used was supplied by Sankyo Company, Tokyo, Japan. The effective molar concentrations of the drugs in the vitreous may be roughly estimated by assuming that the injected materials were distributed uniformly over a vitreous body of average dimensions $1.7 \mathrm{ml}$. The effective concentrations of the chemicals calculated in this fashion was respectively $5.0 \times 10^{-3} \mathrm{M}$ and $1.8 \times 10^{-8} \mathrm{M}$ for lidocaine and tetrodotoxin. Within several minutes following the injection of each of the drugs the SLONP, equally with the subsequent components, was almost abolished or depressed drastically, while the ERG inclusive of the ERP was only slightly or little affected by the application of the drugs. The possibility that the effects of intravitreous injections of the drugs were due to an increase in the 
intraocular pressure of the eye tested rather than the drugs themselves, could be eliminated by control experiment, in which $100 \mu$ l normal saline solution was intravitreously given. The control experiment had no significant effect. When the rabbit was subjected to anoxia, all the potentials of the optic nerve declined readily. In that event both the SLONP and the early-on-wave may diminish at different rates. In the earlier stages of anoxia, for instance, the decay rate of the SLONP was found to be higher compared to that of the early-on-wave. On the basis of the findings mentioned above, it may be considered that the SLONP as well as the following components of the optic nerve have little dealing with the volume conductor effect, and it is highly conceivable that the SLONP is mainly due to a population response of optic nerve bursts.

Contrary to the depressive influences of nerve blockaders on the optic nerve responses some components may be enhanced by picrotoxin. As to the influences of the drugs on the SLONP and early-on-wave, intravitreous injection of $100 \mu 1$ of $2.4 \times 10^{-2} \%$ picrotoxin solution was found to augment not only the latter potential considerably, but also at least the main portion of the SLONP significantly (FIG. 6). During this time the b-wave was also significantly depressed in association with a reduction of the oscillatory potential. There was only a slight if any effect of picrotoxin on the initial part of the SLONP. The effective concentration of picrotoxin in the vitreous body was approximatively assessed to be about $1.2 \times 10^{-5} \mathrm{M}$, provided that the injected material was diluted to a vitreous body volume of about $1.7 \mathrm{ml}$. The abovesaid picrotoxin-effects on the two potentials of the optic nerve could be seen likewise when the optic nerve had been sectioned posterior to the recording electrode tip.

The lines of evidence obtained from what has been debated may signify that the SLONP is essentially composed of optic nerve bursts. In order to substantiate this contention microelectrode experiments were made. The microelectrode used in this study picked up a few units responses at the same time. At intensities slightly below the threshold (about $-0.7 \log$ unit) of the SLONP, a discharge of impulses with a latency of about $11 \mathrm{msec}$ was seen which probably contributes the early-on-wave as the compound spike potential of the optic nerve. Beyond this intensity a short latency discharge activity preceding the early-on-wave was observed mostly in the central and/or ventral area of the optic nerve (FIG. 7), and consequently there was a jump to a latency of about 4.5-5.0 msec. Increasing of the stimulus intensity decreased slightly the latency of the early discharge. The timing and duration of the short latency discharge appeared to be comparable with those of the SLONP (FIG. 7). The threshold of the short latency optic nerve discharge was shown, by simple inspection of the firing patterns following single flashes, to approximate that of the SLONP so far as could be examined. The density of impulses was higher at stronger 

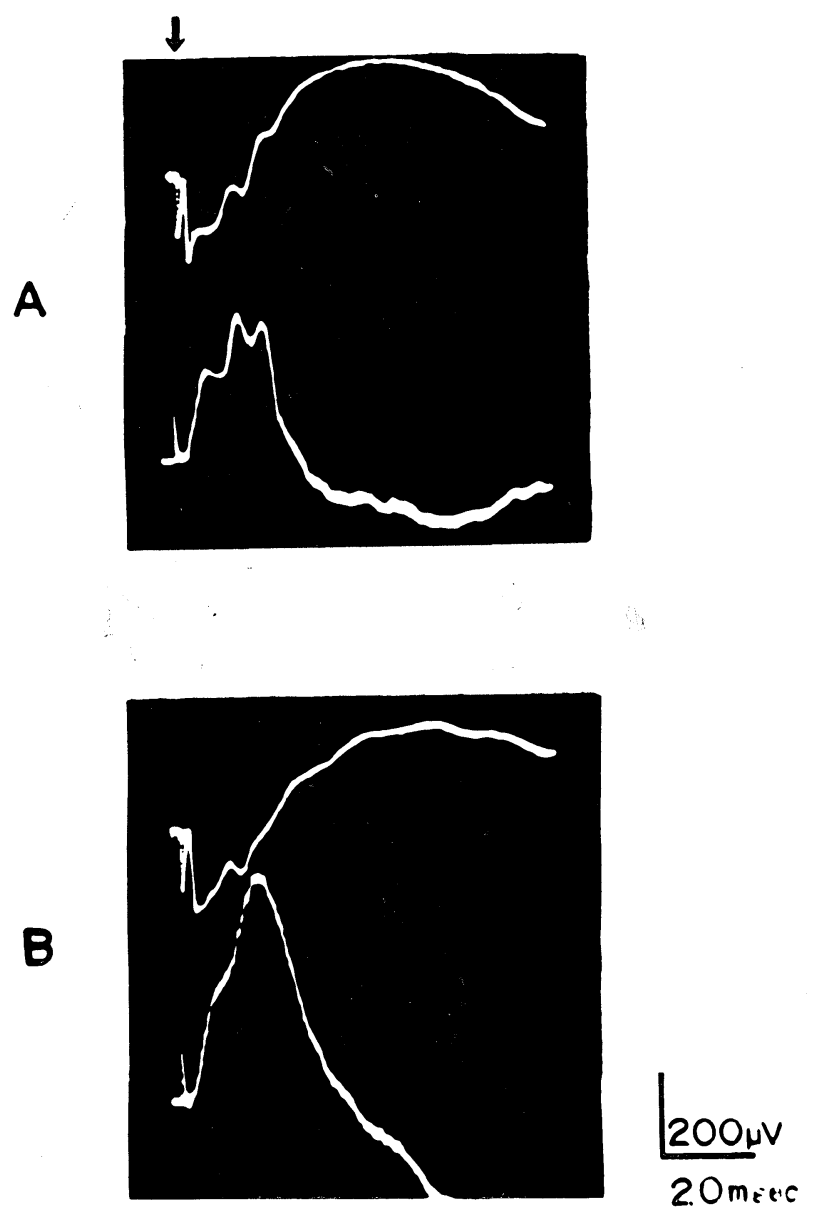

FIG. 6. Effects of picrotoxin on the ERG and optic nerve potential including the short latency optic nerve potential (SLONP). A: ERG (upper trace) and optic nerve potential (lower trace) before the injection of picrotoxin. In the ERG record, the early recepter potential and the usual ERG components (the a- and b-wave, and the oscillatory potential) are seen. In the record for the optic nerve response, there are the SLONP followed by the early-on-wave on which wavelets are superimposed. B : $100 \mu 1$ of $2.4 \times 10^{-2} \%$ picrotoxin saline-solution was injected into the vitreous body. Records were taken 10 minutes after the injection. Both b-wave and the oscillatory potential was depressed noticeably, while there are no change in the ERP and little if any deterioration in the a-wave (see upper trace). Note that the early-on-wave was enhanced to be approximately doubled in size, associated with disappearance of the wavelets. The peak amplitude of the SLONP was also augmented considerably. Arrow indicates the onset of light stimulus. Time constant: 0.3 sec. Positivity: upwards.

stimulus intensities. But it is not accurately assessed whether the observed change in the discharge is preponderantly due to changes in the firing rates of individual fibers or to changes in the number of firing fibers, because the present microelectrode study is a preliminary one with obvious limitations, 


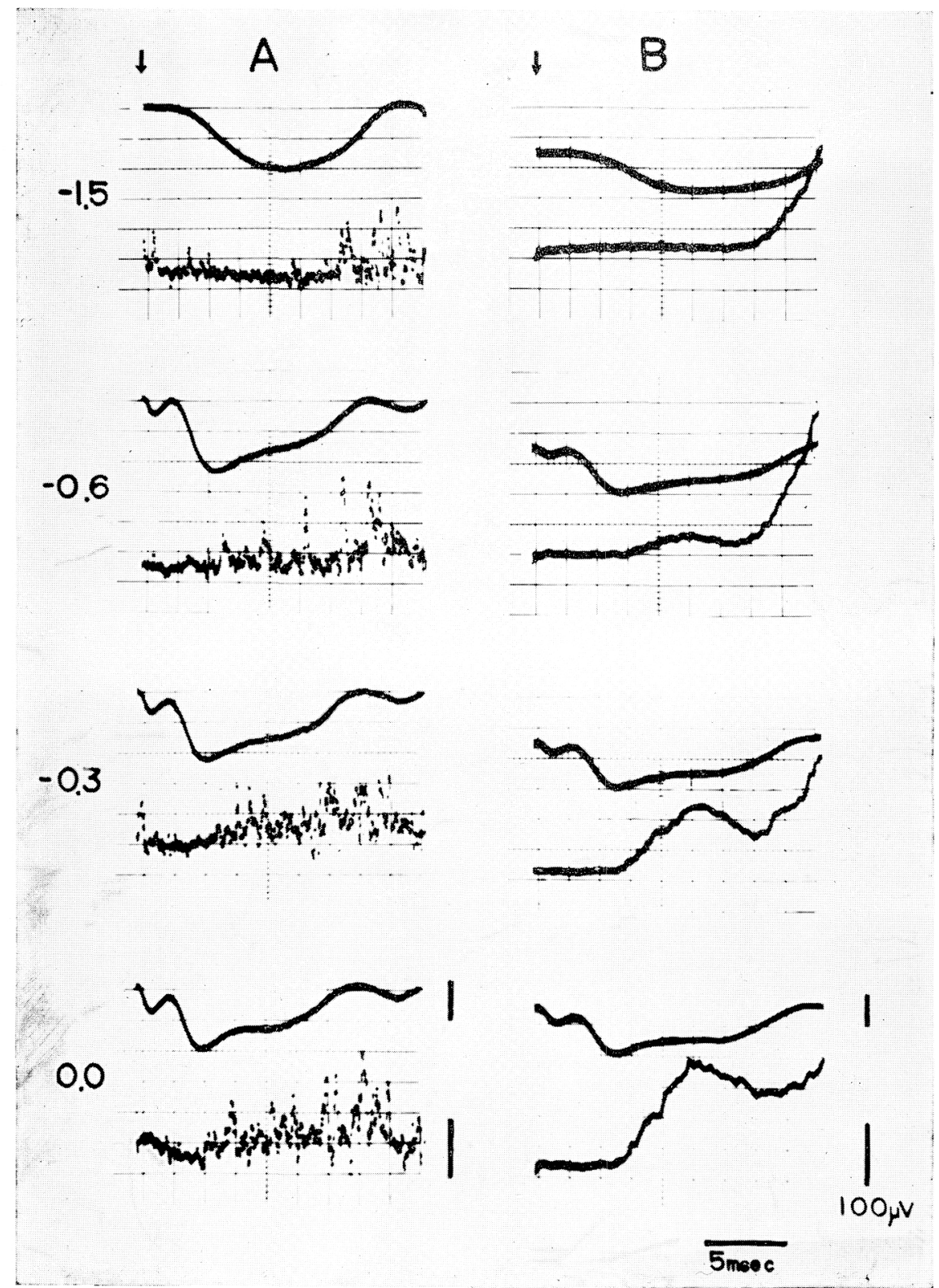

FIG. 7. Combined recording of the ERG and optic nerve potential of the albino rabbit. Upper recording of each set presents ERG, and lower one optic nerve potential. Optic nerve discharges were recorded with a microelectrode (A). Stimulus is indicated by an arrow. Numerals at left indicate log stimulus intensities. At an intensity of $-1.5 \mathrm{log}$ unit, discharge activity begins $11.0 \mathrm{msec}$ after the stimulus. At higher stimulus intensity ( -0.6 to $0.0 \mathrm{log}$ unit), there appears a burst activity having a latency of $4.5-5.0 \mathrm{msec}$. Increasing of stimulus intensity increases the density of impulses. The onset of the burst activity is synchronous with that of the short latency optic nerve potential (SLONP) shown in lower traces in record B. Records $\mathrm{A}$ and $\mathrm{B}$ were taken from different rabbits, Time constant: $0.3 \mathrm{sec}$. Positivity: upwards. 


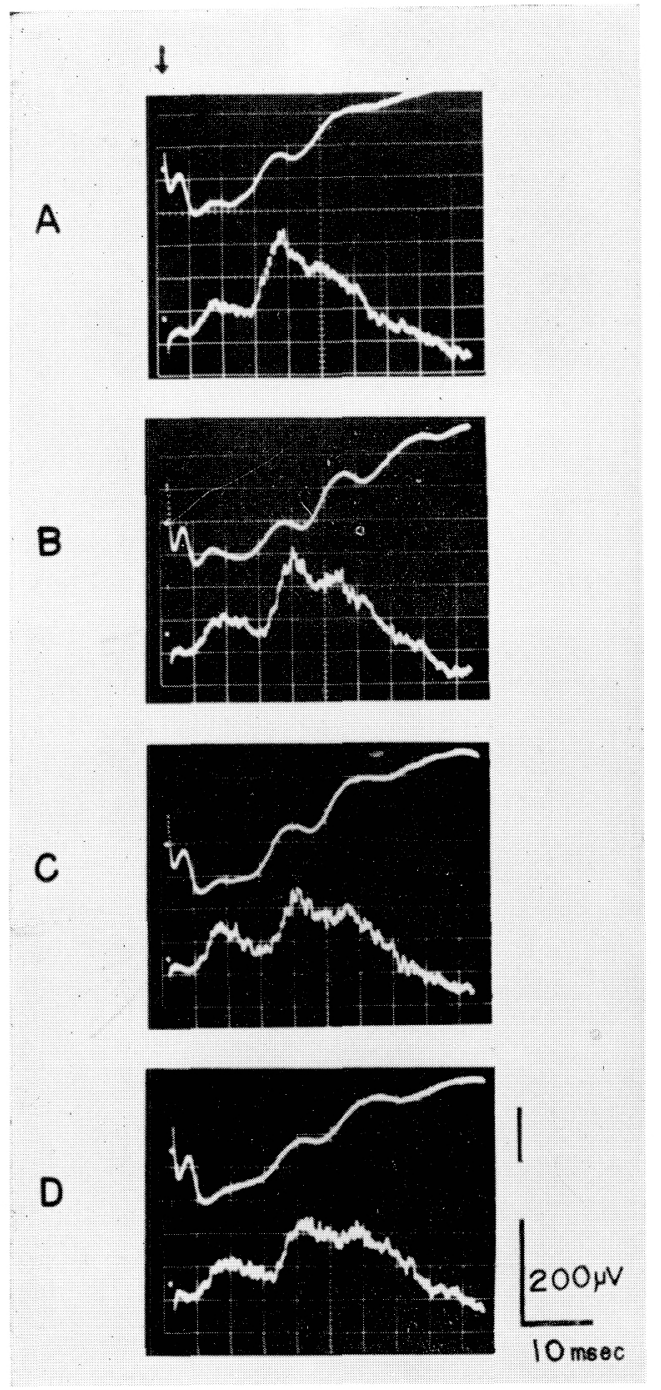

FIG. 8. Effects of intravitreous injection of strychnine on the ERG (upper traces) and the optic nerve potentials including the SLONP (lower traces) in the albino rabbit. A: Before injection. The ERG is started by the early recepter potential followed by the a-wave and the b-wave on which the oscillatory potential is superimposed. The light-induced optic nerve response begins with the SLONP (the relatively small positive hump) which is followed by the early-onwave having a latency of $11.0 \mathrm{msec}$. Intensity of stimulus: $0.0 \log$ unit, which is approximately 108.5 times that of the scotopic b-wave threshold. After injection, B: $1.2 \times 10^{-6} \mathrm{M}$, C : $1.2 \times 10^{-4} \mathrm{M}$, D : $1.2 \times 10^{-3} \mathrm{M}$. Molar concentrations indicate the effective concentrations of strychnine in the vitreous body, provided that the injected materials are distributed uniformly over a vitreous body of average dimensions $1.7 \mathrm{ml}$. After administrations of strychnine, the earlyon-wave was found to be depressed in amplitude and to be lengthened in latency. With the treatment of strychnine, however, the SLONP was little affected in amplitude as well as in latency. Time constant: $0.3 \mathrm{sec}$. Positivity: upwards.

chief of which is the failure of the method to distinguish clearly single unitresponse. The depressive effects of blockaders (lidocaine and tetrodotoxin) on the short latency optic nerve discharge were recognized with the minimum doses at which both the early-on-wave and the SLONP were abolished.

For these reasons we may consider that the physiological and pharmacological properties of the SLONP are in principal agreement with those of the short latency optic nerve discharge. Such a parallelism indicates that the SLONP is essentially identical with the population response due to the short latency optic nerve discharge. The "killed end effect" may explain the positivity of the SLONP as recorded monopolarly. 


\section{DISCUSSION}

This study has revealed that at least a part of the optic nerve fibers in the central and/or ventral area of the optic nerve can produce the SLONP in response to diffuse strong flash stimulation of the retina. A similar potential is also demonstrated in the optic nerve of the normal pigmented rabbit (YONEMURA and TSUCHIDA, unpublished). It may not appear likely that the failure to detect the SLONP in the dorsal area of the optic nerve lying in the cranial cavity is ascribable to injury, as the early-on-wave has been recorded invariably there and has been shown to maintain a considerable size. Under the conditions of the present experiments, therefore, the short latency optic nerve discharge is scarcely discharged in the dorsal area. Most of the fibers which can produce the SLONP may be localized in the central and/or ventral area of the optic nerve so far as the intracranial portion is concerned. This shows that the optic nerve fibers involved in the response of the visual system to diffuse flash light are grouped into two classes on the basis of their different response to strong photic stimulation of the retina. The one group generates the short latency bursts in response to intense retinal illumination, and other does not. The fibers belonging to the former class may be labeled the SLONP. producing fibers for convenience of description.

The point whether the SLONP is relevant or not to the myelination of the intraocular portion of fibers, which is a regular occurrence in the rabbit retina (BERLINer, 1931; THOMSON, 1953; PRINCE, 1964), is an open question. It is felt that the further work is needed to make out the accurate distribution of the fibers in the nerve and retina.

According to the accepted teaching, there is good reason to believe that the light sensitive structures of the vertebrate retina are the rods and cones. To our knowledge there has been little authoritative information available indicating that retinal elements except visual cells, in the vertebrate retina, might be directly excited by visible rays. Besides, light intensities in the range lying over an extent of $9 \mathrm{log}$ units above the scotopic b-wave threshold might still be of some functional significance, since it is believed in general that the eye can discriminate well enormous ranges of light intensity up to 10 log units (Dowling and BoycotT, 1966). Notwithstanding one might. imagine that such intense flashes as those employed in the present study can stimulate directly structures proximal to the photoreceptors to participate in producing the SLONP. The localization of the SLONP in the optic nerve may afford a clue to this problem. If the direct stimulation of non-receptor systems can actually contribute to the SLONP, one would expect, on assumption that they are distributed over the retina, that the SLONP arises not only in the central and/or ventral area but also in the remaining area of the optic nerve, since diffuse retinal stimulation ought to illuminate all retinal structures. The 
localization of the SLONP, which has been shown in the present study, however, is contrary to what was expected, seeming to be unfavorable for the foregoing presumption. The present study has shown that, in the dynamic range of the SLONP amplitude vs log stimulus intensity curve, the amplitude of the $\operatorname{ERP}\left(R_{2}\right)$ is presented to be directly proportional to stimulus intensity, and that beyond this range the $R_{2}$ becomes saturated (FIG. 5). These findings may be indicative of a close relationship between the SLONP and the ERP which is assumed to result from absorption of light by the photopigment of the outer segments of the visual cells (PACK and Cone, 1964; BROWN, WATANABE and MURAKAMI, 1965). Taking account of the afore-going arguments, it would be presumptuous to consider the possibility that the SLONP is interpreted exclusively in terms of the hypothetical direct photoactivation of nonreceptor systems in the retina. Instead of assuming a merely speculative possibility, it appears to be rather logical at present to assume conventionally that the SLONP is primarily mediated by visual cells. We are inclined to recognize the second possibility, although the final conclusion is not drawn here concerning the problem.

The experiments of optic nerve transection indicate that, among the SLONP-producing fibers, there may be few, if any, efferent fibers, and accordingly the great majority of the SLONP-producing fibers run centripetally. YONEMURA, YAMADA and FUJIMURA (unpublished) have recently attempted electrophysiological recordings from single units in the lateral geniculate body and have shown that the SLONP-producing fibers, at least partly, reach the opposite lateral geniculate body. In spite of the high threshold of the SLONP, it is not unreasonable to suppose that potential would play some role in conveying receptor messages towards the brain when the visual cells absorb light energy delivered by intense flash light, on the premise that the SLONP is mediated by visual cells.

The problem as to whether it is possible for the b-wave in the ERG to determine the excitation of ganglion cells and consequently the optic nerve discharge through the optic nerve is a matter of controversy (GRANIT, 1947, 1962 ; Schubert, 1953; Ponte and Monaco, 1964; Poppel and Maffei, 1967). In the dynamic range of the SLONP amplitude vs log stimulus intensity relationship, both the a- and b-waves remain unchanged in amplitude with little regard to the intensity of stimulating light (FIG. 2). Probably the amplitude of the SLONP little correlates to the size of usual ERG components. This means that the determination of the size of the SLONP depends predominantly upon unknown factors, rather than upon ordinary ERG components. As mentioned above, the SLONP can evidently precede the start of the b-wave when the latency of the b-wave has been measured, as usual, from the peak of the a-wave on the basis of GRANIT's theory, according to which the a- and b-waves are the outcome of the algebraic sum of two opposite sign components (PII and 
PIII). If the preceding argument is sound, it may be difficult to understand the temporal relationship between the b-wave and the SLONP by the assumption that the b-wave participates in producing the SLONP. Additionally it has been demonstrated that a local application of picrotoxin to the retina can obviously amplify the optic nerve potentials including the SLONP, accompanied by a depressed b-wave in the ERG. This seems to favor the view that, as far as concerns the rabbit retina poisoned with picrotoxin, the b-wave cannot represent the event which is directly responsible for ganglionic cell activation.

Since the ganglionic cells appear to be definitely excluded as the source of the conventional ERG (GRANit and HELme, 1939; GRANiT, 1959, 1962) the loss of ERG must reflect changes in the function of structures distal to the ganglion cells. Thus the deterioration of the ERG, which is caused by picrotoxin, should be attributed to the action of picrotoxin on structures except the ganglion cells. Picrotoxin in low concentration has been reported to depress presynaptic inhibition of the spinal cord (Eccles, 1964). According to PECCISAAVEDRA, WiLson and Doty (1966) picrotoxin depresses the presynaptic inhibition in the monkey lateral geniculate body. IWAMA, SAKAKURA and KASAMATSU (1965), on the other hand, could not obtain conclusive evidence suggestive of the effects of picrotoxin on the presynaptic inhibitory mechanism in the cat lateral geniculate body because of inevitable side-effects of the drug. It has been a matter of speculation whether there is a presynaptic inhibition in the retina. Based on his pharmacological study, HEISS (1967) surmised that this type of inhibition exists in the cat retina. The present study has revealed that picrotoxin in low concentration enhances the potentials of the rabbit optic nerve. On the other hand strychnine was found to exert little or no effects on the SLONP and a rather slightly depressive action on the subsequent optic nerve potentials, when $100 \mu \mathrm{l}$ of $0.7 \%$ strychnine was given intravitreously (Yonemura and Tsuchida, unpublished. Fig. 8). In this case the effective concentration in the vitreous body would be calculated $1.2 \times 10^{-6}-1.2 \times 10^{-3} \mathrm{M}$. Hence the enhancing picrotoxin-effects on some of the light-induced potentials of the rabbit optic nerve might possibly be explained at least partly by assuming that picrotoxin depresses a hypothetical presynaptic inhibitory mechanism in the retina, although further verification of such a mechanism in the synapses of the retina is not available at present. Naturally the possibility is not entirely excluded here that picrotoxin might act directly on the intraocular portions of the optic nerve fibers and might result in the accentuation of the compound spike potentials of the optic nerve. The two possible reasons for the accelerating picrotoxin effects on the responses may not be mutually exclusive, and the problem is left unsettled. 


\section{SUMMARY}

With single flashes from a xenon discharge tube the electroretinogram (ERG) and light-induced optic nerve responses were recorded in the albino rabbit. The experiments were carried out in a dark room.

1. The early receptor potential (ERP) in the rabbit consisted of a small positive potential followed by a large negative swing. The second phase of the ERP was succeeded by the a-wave with a latency which is as short as about $1.6 \mathrm{msec}$.

2. The conventional "compound spike potential of the optic nerve", when induced with flash light, contains 1) the late-on-wave which is present only on low illumination and 2) the early-on-wave on which rhythmic wavelets are superimposed. The threshold of the wavelets appeared to approximate that of the oscillatory potential in the ERG. With increase of stimulus intensity the latency of the early-on-wave tended to decrease, finally approaching the absolute minimum latency (about $11 \mathrm{msec}$ ).

3. When the stimulus intensity was raised up to an level sufficient for producing an ERP of considerable size, a rapid potential with a latency of about 4.5-5.0 msec, at a tentative estimate, was found to emerge preceding the earlyon-wave in the optic nerve potential. The new potential which may be called provisionally the short latency optic nerve potential (SLONP) was consistently recordable in the central and/or ventral area of the optic nerve, but scarcely detectable in the dorsal area. The amplitude of the SLONP was linearly related to the log of stimulus intensity in the dynamic range where the slope of amplitude vs log intensity is steepest. In this range the amplitude of the negative phase of the ERP was found to be proportional to stimulus intensity. 4. The SLONP, along with the subsequent optic nerve potentials, were abolished with both nerve blockaders (lidocaine and tetrodotoxin) in low concentrations on their application to the retina. During this time the ERG components including the ERP were little affected.

5. The foregoing results, coupled with other data inclusive of the findings obtained by the microelectrode experiments described in this study, indicate that the SLONP is the population response due to a short latency optic nerve discharge arising from particular optic nerve fibers, most of which leave the retina to pass through the contralateral optic nerve tract towards the brain.

6. Differences between the SLONP and the early-on-wave in latency, lightthreshold, density function, vulnerability to anoxia, all suggest that the two potentials are distinct components.

7. It was shown that there is some correlation between the amplitude of ERP and that of the SLONP. The functional significance of the SLONP was discussed.

8. The comparative studies of the SLONP and the b-wave, which were ob- 
tained with regard to density functions and other aspects, may indicate that the two events behave independently.

9. Picrotoxin in low concentration, when applied topically to the retina from the vitreous side, could give rise to enhancing effects on optic nerve potentials. The possibility was discussed that, in the retina, there might be a presynaptic inhibitory mechanism which can be depressed by picrotoxin.

We wish to express deepest appreciation to Professor Yoshi KURACHI for making this study possible and for his invaluable advice and encouragement throughout the course of this experiment. cation.

A part of the expense of this work was defrayed by a grant of Ministry of Edu.

\section{REFERENCES}

1) Adrian, E.D. (1946). Rod and cone components in the electric response of the eye. J. Physiol., $105:$ 24-37.

2) Adrian, E. D. and Matthews, R. (1927a). The action of light on the eye. I. The discharge of impulses in the optic nerve and its relation to the electric change in the retina. J. Physiol., 63: 378-414.

3) Adrian, E. D." And Matthews, R. (1927b). The action of light on the eye. II. The processes involved in retinal excitation. J. Physiol., 64:279-301.

4) ARden, G. B. AND Brown, K. T. (1965). Some properties of components of the cat electroretinogram revealed by local recording under oil. J. Physiol., 176: 429-461.

5) Bartley, S. H. And Bishop, G. H. (1942). Some features of the optic nerve discharge in the rabbit and cat. J. cell. and comp. Physiol., 19: 79-93.

6) Berliner, M. L. (1931). Cytologic studies on retina; normal co-existence of oligodendroglia and myelinated nerve fibers. Arch. Ophth., 6: 740-751.

7) Bernhard, C. G. (1940). Contribution to the neurophysiology of the optic pathway. 1. Acta physiol. scand. 1. Suppl., 1:5-94.

8) Bernhard, C. G. (1942). Temporal sequence of component potential in the frog's retina and the electrotonic potential in the optic nerve. Acta physiol. scand. 3:301-310.

9) Brown, K. T. (1965). An early potential evoked by light from the pigment epithelium-choroid complex of the eye of the toad. Nature, 207:1249-1253.

10) BRown, K. T. AND CRAWford, J. M. (1967a). Intracellular recording of rapid light-evoked responses from pigment epithelium cells of the frog eye. Vision Res., $7: 149-163$.

11) Brown, K. T. And Crawford, J.M. (1967b). Melanin and rapid light-evoked responses from pigment epithelium cells of the frog eye. Vision Res., 7: 165-178.

12) Brown, K. T. and Gage, P. W. (1966). An earlier phase of the light-evoked electrical response from the pigment epithelium-choroid complex of the eye of the toad. Nature, $211: 155-158$.

13) Brown, K. T. And Murakami, M. (1964a). A new receptor potential of the monkey retina with no detectable latency. Nature, $201: 626-628$.

14) Brown, K. T. And Murakami, M. (1964b). Biphasic form of the early receptor potential of the monkey retina. Nature, 204:739-740.

15) BRown, K. T. ANd Wiesel, T.N. (1961). Localization of origins of electroretinogram components by intraretinal recording in the intact cat eye. J. Physiol., 158: 257-280.

16) Brown, K. T., Watanabe, K. and Murakami, M. (1965). The early and late receptor potentials of monkey cones and rods. Cold Spring Harbor Symposia on 
Quantitative Biology, 30 : 457-482.

17) Cone, R.A. (1964). Early receptor potential of the vertebrate retina. Nature, $204: 736-739$.

18) Cone, R.A. (1965). The early receptor potential of the vertebrate eye. Cold Spring Harbor Symposia on Quantitative Biology, 30: 483-491.

19) Crapper, D. R. AND Noell, W. K. (1963). Retinal excitation and inhibition from direct electrical stimulation. J. Neurophysiol., 26 : 924-947.

20) Doty, R. W. AND Kimura, D.S. (1963). Oscillatory potentials in the visual system of cats and monkeys. J. Physiol., 168: 205-218.

21) Doty, R. W., Kimura, R. S. and Mogenson, G. J. (1964). Photically and electrically elicited responses in the central visual system of the squirrel monkey. Exp. Neurol., $10: 19-51$.

22) Dowling, J. E. ANd Boycott, B. B. (1966). Organization of the primate retina: electron microscopy. Proc. Roy. Soc., 166B : 80-111.

23) Ebrey, T. G. And Cone, R. A. (1967). Melanin, a possible pigment for the photostable electrical responses of the eye. Nature, 213:360-362.

24) Eccles, J.C. (1964). “The Physiology of Synapses", Springer-Verlag, Berlin.

25) Galloway, N.R. (1967). Early receptor potential in the human eye. Brit. J. Ophthal., $51: 261-264$.

26) Granit, R. (1947). "Sensory Mechanismus of the Retina", Hafner Publishing Comp., New York.

27) Granit, R. (1959). “Neural Activity in the Retina”, Neurophysiology, Handbook of Physiology, Section 1: Volume 1: 693-712. Amer. Physiological Society, Washington D. C.

28) Granit, R. (1962). “The Visual Pathway, a Confrontation of Physiology with Anatomy", The Eye. II. Edited by Davson, H., 535-763. Academic Press, New York.

29) Granit, R. And Helme, T. (1939). Changes in retinal excitability due to polarization and some observations on the relation between the processes in retina and nerve. J. Neurophysiol., 2 : 556-565.

30) Hartline, H.K. (1938). The response of single optic nerve fibers of the vertebrate eye to illumination of the retina. Amer. J. Physiol., 121: 400-415.

31) Heiss, W. D. (1967). Daueraktivität retinaler Neurone unter Einwirkung von Strychnin und Picrotoxin. Vision Res., $7: 583-598$.

32) Imama, K., Sakakura, H. And Kasamatsu, T. (1965). Presynaptic inhibition in the lateral geniculate body induced by stimulation of the cerebral cortex. Jap. J. Physiol., $15: 310-322$.

33) KAWASAKI, K. (1966). The early potential in the human electroretinogram. Acta soc. ophth. jap., 70 : 1594-1601; ISCERG News Letter, 7, No. 1, 29.

34) KAwASAKI, K. (1967). The early potential in the albino rabbit ERG. Acta soc. ophth. jap., $71: 679-688$.

35) Lennox, M. A. (1958). The on responses to colored flash in single optic tract fibers of cat: correlation with conduction velocity. J. Neurophysiol., 21 : 70-84.

36) Müller-Limmroth, W. (1959). “Electrophysiologie des Gesichtssinns”, SpringerVerlag, Berlin.

37) Murakami, M. And Kaneko, A. (1966a). Subcomponents of P III in cold-blooded vertebrate retinae. Nature, 210: 103-104.

38) Murakami, M. and Kaneko, A. (1966b). Differentiation of P III subcomponents in cold-blooded vertebrate retinas. Vision Res., 6:627-636.

39) Nakamura, Y., Nakajima, S. ANd Grundfest, H. (1965). The action of tetrodotoxin on electrogenic components of squid giant axons. J. Gen. Physiol., 48: 
985-996.

40) Noell, W.K. (1953). "Studies on Electrophysiology and the Metabolism of the Retina", Project Number 21-1201-0004, Report Number 1, UASF School of Aviation Medicine Randolph Field, Texas.

41) Noell, W. K. And Chinn, H. I. (1950). Failure of the visual pathway during anoxia. Amer. J. Physiol., 161: 573-590.

42) Ogawa, T., Bishop, P. O. and Levick, W. R. (1966). Temporal characteristics of responses to photic stimulation by single ganglion cells in the unopened eye of the cat. J. Neurophysiol., $29: 1-30$.

43) PAK, W. L. AND CONE, R. A. (1964). Isolation and identification of the initial peak of the early receptor potential. Nature, $204: 836-838$.

44) Pecci-Safyedra, J., Wilson, P. D. And Doty, R. W. (1966). Presynaptic inhibition in primate lateral geniculate body. Nature, 210:740-742.

45) Ponte, E. And Monaco, P. (1964). A study of relationship between electroretinogram and optic nerve discharge. Ophthalmologica, 147 : 57-66.

46) Poppel, R. E. And Maffei, L. (1967). Retinal responses with different background light and psychophysical correlation. Arch. ital. Biol., $105: 189-200$.

47) PRince, J.H. (1964). “The Rabbit in Eye Research", Charles, C. Thomas Pub. Springfield, Illinois.

48) Schubert, G. (1953). Über den retinalen Auslösungsmechanismus der Optikus Aktivität. Graefes Arch. Ophth., $154: 125-134$.

49) Steinberg, R.H. (1966). Oscillatory activity in the optic tract of cat and light adaptation. J. Neurophysiol., 29 : 139-156.

50) Thomson, L. C. (1953). The localization of function in the rabbit retina. $J$. Physiol., 119: 191-209.

51) Yokoyama, M., Kaneko, K. And Nakai, Y. (1963). On- and off-effect on mass response of the optic nerve of rabbit. Mie Med. J., 12: 257-272.

52) Yokoyama, M., Kaneko, K. And NAKAI, Y. (1964). The oscillatory potential in the retina and the optic nerve of rabbit. Mie Med. J., 13: 109-122.

53) Yonemura, D. And Hatta, M. (1966a). Localization of the minor components of the frog's electroretinogram. Proceedings of the 4th ISCERG Symposium (J. J. O., 10, Suppl., Tokyo, 1966) : 149-154.

54) Yonemura, D. And Hatta, M. (1966b). Studies of the minor components of the frog's electroretinogram. Jap. J. Physiol., 16: 11-22.

55) Yonemura, D. And KawAsaki, K. (1967). The early receptor potential in the human electroretinogram. Jap. J. Physiol., $17: 235-244$.

56) Yonemura, D. And Tsuchida, Y. (1967). A new early fiber potential in the rabbit optic nerve. Jap. J. Ophth., 11, 166-172.

57) Yonemura, D., Kaw Asaki, K. And Hasui, I. (1966). The early receptor potential in the human ERG. Acta soc. ophth. jap., 70:766-768; ISCERG News Letter, 7, No. 1, 29.

58) Yonemura, D., Masuda, Y. And Hatta, M. (1963). The oscillatory potential in the electroretinogram. Jap. J. Physiol., 13: 129-137.

59) Yonemura, D., Tsuchida, Y. And Fujimura, K. (1967). A study of the a-wave in the rabbit's ERG. Acta soc. ophth. jap., 71: 98-100.

60) Yonemura, D., Tsuchida, Y., Fujimura, K. and Yamada, Y. (1967). New early potentials preceding the ordinary on-responses in visual pathways of the albino rabbit. Acta soc. ophth. jap., 71: 230-234; ISCERG News Letter 8, No. 1, 19.

61) Yonemura, D., Tsuchida, Y., Yamada, Y. and Fujimura, K. (1967). The slow negative potential recorded from the rabbit optic nerve. Acta soc. ophth. jap., 71 : $359-362$. 